\title{
LA OPERACIÓN CÓNDOR Y EL TERRORISMO DE ESTADO*
}

\author{
THE CONDOR OPERATION AND STATE TERRORISM
}

HENRY TORRES-VÁSQUEZ**

\section{Resumen}

Objetivo. Analizar la realidad histórica de las actividades criminales efectuadas por integrantes de las fuerzas militares desde 1975 en algunos países de Suramérica. La persecución trasnacional a los presuntos terroristas, comunistas y en general disidentes de los diferentes gobiernos como generadores de inseguridad en la región, ocasionó que estos fueran desaparecidos, asesinados y torturados. Metodología. Este artículo hace parte de una investigación socio-jurídica, en la que se utilizó un método jurídico-doctrinal. Resultados. En la denominada "Operación Cóndor" como forma de alcanzar seguridad, degeneró en la comisión de crímenes que fueron cometidos utilizando el fenómeno del terrorismo de Estado, el cual subyace en las prácticas de terror realizadas en el continente con el apoyo de los EE.UU. Conclusión. Para eliminar estas prácticas es fundamental la intervención de tribunales internacionales de tal forma que se evite la impunidad frente a estos graves crímenes de naturaleza internacional.

Palabras clave: Operación Cóndor, terrorismo de Estado, Corte Interamericana de Derechos Humanos, impunidad.

\begin{abstract}
Objective. To analyze the historical reality of criminal activities carried out by members of the military forces since 1975 in some countries of South America. The transnational chase of the alleged terrorists, communists and generally dissidents of the different governments as generators of insecurity in the region, caused them to be disappeared, killed, and tortured. Methodology. This article is part of a socio-legal research in which a legal-doctrinal method was used. Results. The so-called " Condor Operation " to achieve security, degenerated into the commission of crimes that were committed using the phenomenon of State terrorism, which underlies the terror practices carried out in the continent with the support of the USA. Conclusion. It is concluded that to eliminate these practices, the intervention of international tribunals is essential in order to avoid impunity in the face of these serious crimes of an international nature.
\end{abstract}

Key words: Operation Condor, State terrorism, Inter-American Court of Human Rights, impunity.

\footnotetext{
*Artículo que hace parte de la investigación "El terrorismo en el sistema interamericano de derechos humanos", investigación financiada por la Universidad La Gran Colombia y dirigida por Henry Torres Vásquez.

** Universidad La Gran Colombia. Bogotá, Colombia. E-mail: henry.torres@ugc.edu.co.

(D) orcid.org/0000-0002-5299-8269 Google Scholar
} 


\section{Introducción}

Es claro que abordar el Plan Cóndor, su génesis y los inconvenientes derivados de la aplicación de justicia a jefes de Estado y jerarcas militares por jueces nacionales o internacionales en materia de crímenes de naturaleza internacional, no es sencillo de explicar, sobre todo si se tiene en cuenta que hoy se aboga por una defensa extrema de los derechos humanos (DH) en la que, por supuesto, quienes han sido violadores de derechos humanos hoy abogan por ellos. Empero, el análisis que sigue se hace desde una óptica de los DH, pero en un examen del terrorismo de Estado efectuado por diferentes gobiernos durante años, inclusive décadas.

Durante todo el siglo XX y profusamente a partir de su segunda mitad, varios hechos de enorme gravedad, en los que los civiles fueron las principales víctimas, marcaron una historia de violaciones a los derechos humanos en Suramérica, que en no pocas ocasiones fue masiva; estas campañas de terror fueron decididas, diseñadas y aplicadas por diferentes gobiernos y provocaron que las relaciones entre los países de este continente fueran casi homogéneas respecto al cómo enfrentar la disidencia política, el inconformismo social y cualquier brote de inadaptación con las políticas neoliberales, estos problemas tuvieron como principal referente las acciones legales y, en muchas ocasiones, criminales propiciadas por los militares en los países del Cono Sur de América.

Los siguientes tres hechos, además de lo ya referido, fueron determinantes. En primer lugar, la guerra fría en la que el anticomunismo pululaba en el continente, el enorme desarrollo mediático de las políticas anticomunistas y la consecuente antipatía a la Unión Soviética, convirtió la lucha contra el comunismo en la bandera del militarismo latinoamericano; el anticomunismo lo entiende Bohoslavsky (2016) como "una fuerza ideológica con adherentes en múltiples capas sociales y tradiciones políticas, y por lo tanto, como un elemento con capacidad potencial para aglutinar a esos distintos aliados sociales y políticos" (p. 37); estos aspectos convirtieron el anticomunismo como parte de la lucha de nacionalistas, que arropadas en diversas ideologías de derecha eran abiertamente militaristas basados, como en adelante se verá, en la doctrina de la seguridad nacional.

En segundo lugar, unas políticas dirigidas por la derecha norteamericana más obstinada en las que los países de la región tenían en la represión la principal fuente de introyección de normas y del miedo a las mismas y, a su vez, de todos los poderes del Estado, especialmente del ejecutivo que con sus amplios poderes dictatoriales podía 'mangonear' a toda la sociedad, aupados por el total control que ejercían en los medios de comunicación masiva.

En tercer lugar, la Doctrina de Seguridad Nacional en el que su gran componente fue el denominado "Plan Cóndor" con el cual se cometieron desapariciones forzadas, torturas, homicidios, etc. Por lo menos estos tres sucesos, y debido a su exacerbada violencia, han 
La Operación Cóndor y el terrorismo de Estado

sido objeto - en las décadas del 90 del siglo pasado hasta ahora- de procesos ante la Corte Interamericana de Derechos Humanos.

Las prácticas de terror y de terrorismo llevadas a cabo por gobiernos en los que el mando militar poseía el poder de facto fueron comunes en varias décadas de la historia del continente en el siglo pasado, sin querer decir que hayan terminado, evidentemente en esta década es mucho menor.

El terrorismo proveniente del Estado provocó innumerables crímenes y solo hasta finales del siglo anterior se vino a saber parte de la verdad de lo ocurrido, al igual que se tuvo varias condenas contra estos criminales. Dentro del terrorismo de Estado:

\footnotetext{
Es muy frecuente la utilización de concepto de democracia, no obstante, este se ha dicho adquiere un matiz especial, los gobiernos terroristas de Estado, en aras de defender el Estado mismo no les importa que estas acciones vayan en parte acompañadas de actos de terrorismo dirigidos contra ciudadanos inermes y, por lo tanto, queda en el ostracismo la locución democracia en su sentido estricto. (Torres, 2010, p. 141)
}

Este aspecto es importante en la medida en que se disfrazan como democráticas las acciones de terror provenientes del gobierno que terminan siendo terrorismo estatal. Con esa orientación emerge la pregunta: ¿La operación Cóndor y los crímenes que fueron cometidos por diversos gobiernos del continente son terrorismo de Estado?

En lo que sigue, se aborda la discusión sobre esas prácticas de terror y de las consecuencias que para las democracias latinoamericanas trajeron estos acontecimientos. Este artículo hace parte de una investigación socio-jurídica, en la que se utilizó un método jurídico-doctrinal, de análisis y síntesis el cual de forma sistemática y con un pensamiento crítico permite referirse a otros aspectos de la operación Cóndor que son complementarias entre sí. El análisis aquí efectuado es holístico fundamentado en doctrina internacional.

\section{Discusión}

\section{El militarismo en el contexto regional de prácticas de terror}

Estados Unidos después de la segunda guerra mundial, emprendió una serie de acciones en todo el mundo, y en Latinoamérica lo hacen de manera preferente en algunos países. América del Sur se vio repleta del auge militarista, especialmente en las décadas del 50 al 80. Esta era la forma de consolidar el liderazgo de aquel país y, por supuesto, la mejor forma de lograr una defensa acérrima de sus intereses geoestratégicos. En ese sentido, el antagonista a vencer 
era el comunismo en la región, y en el plano de los países regionales comenzaba a aflorar en el terrorismo doméstico un 'enemigo' interno que, de la mano de la ideología comunista, era visto por el gobierno norteamericano como una enorme amenaza y los gobiernos locales así lo trasmitían a sus ciudadanos. Para enfrentar a ese 'enemigo' se desarrollaron programas que de manera sistemática querían a toda costa evitar el 'contagio' del comunismo, como bien señala Bohoslavsky (2016): "El principal estímulo para el desarrollo de las fuerzas anticomunistas después de 1959 provino de un conjunto de alteraciones en el orden internacional” (p. 44); en razón del triunfo de la revolución cubana y del furor continental respecto a ese tipo de lucha, el comunismo era el más temido enemigo.

En Colombia para evitar la posibilidad de acceder a instancias de poder por parte de comunistas y por medio del programa "Alianza para las Américas"

\begin{abstract}
Se introdujo en el país la figura del "enemigo interno" que se concretó en el llamado Plan Lazo, cuya finalidad era acabar militarmente los reductos de las guerrillas liberales y atajar la avanzada comunista, como constaba en un volante repartido en Villarrica, a comienzos de 1962. (Varela y Duque, 2011, p. 4)
\end{abstract}

Los 'comunistas' pasan a ser un 'enemigo' la consecuente forma de enfrentarlo es con la

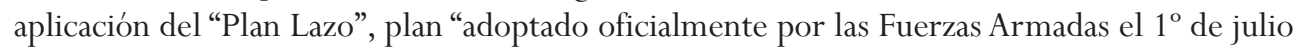
de 1962” (Varela y Duque, 2011, p. 176). En 1964 surgen las Fuerzas Armadas Revolucionarias de Colombia (FARC), grupo armado revolucionario el cual, recuerdan Varela y Duque, estaba constituido "principalmente por campesinos de tendencia comunista, articulados orgánicamente al PC, que desarrollaban una lucha de autodefensa armada para conservar sus predios en áreas de colonización y para evitar la acción tanto de latifundistas como del ejército" (Vélez, 2014, p. 33). Bajo la consideración de la Unión Soviética como el gran enemigo y en la región Cuba sin necesidad de intervenciones militares directas los EE.UU. lograron que los países de la región crearan y durante décadas tuvieran su propio enemigo externo e interno. Así fue que el enemigo era el hermano. Luego, fue muy importante la guerra de baja intensidad hasta llegar a la hoy conocida guerra contra el terrorismo.

El terrorismo de Estado como ejercicio criminal de diferentes gobiernos latinoamericanos tuvo en la denominada "Operación Cóndor" una de las formas de expresión más horrorosa y generalizada.

En los años 70 del siglo anterior, "los monopolios y oligopolios generaban diversos embates a los empobrecidos, incomunicados y descapitalizados países de la región” (Galeano, 1979, p. 398). Bajo la presión de los EE.UU., recuerda Eduardo Galeano que "Letelier decía que la economía chilena está ahora más concentrada y monopolizada que en las vísperas del gobierno de Allende. 
La Operación Cóndor y el terrorismo de Estado

Negocios libres como nunca: América Latina, la libertad de empresa es incompatible con las libertades públicas" (Galeano, 1979, p. 421). Esas libertades eran suprimidas, modificadas temporal o definitivamente de acuerdo con la conveniencia del gobierno.

Según Michael Ignatieff, en Argentina en los años 70 había terrorismo de carácter marxista, lo que provocó que las élites de poder se involucraran en una represión indiscriminada, lo que conllevó a una dictadura militar, "los militares utilizaron el pretexto de la crisis económica y la insurrección terrorista para instaurar el reino de terror en Argentina, basado en torturas y desapariciones" (Ignatieff, 2005, p. 97).

El progresivo aumento del número de jefes de Estado militares en el continente y, en su defecto, el mantener a muchos de estos dentro de las elites del poder acrecentó las luchas fratricidas generadas desde los gobiernos militaristas. La violencia política en la región conllevó a la ejecución del terrorismo de Estado, señalan Abramovich y Guembe (2006) que mientras Uruguay se caracterizó por el encarcelamiento político en condiciones infrahumanas, Chile sobresalió por las ejecuciones extrajudiciales y "Argentina por la desaparición forzada de personas y la clandestinidad de la represión” (Abramovich y Guembe, 2006, p. 53).

En Argentina la dictadura militar practicó el terrorismo de Estado, para el efecto utilizó las fuerzas armadas y a grupos parapoliciales los cuales reprimían de manera clandestina a los opositores. Recuerdan Abramovich y Guembe (2006) que para garantizar "el encubrimiento y el silencio, se hizo participar a todos los integrantes de las fuerzas armadas de este plan integral de represión" (p. 53).

En los países objetivo principal de la Operación Cóndor, la impunidad era rampante, dentro de esa dinámica criminal:

Pinochet promulgó una auto-amnistía que aún está vigente. En la Argentina, los militares se sublevaron para obligar al gobierno de Raúl Alfonsín a que pusiera fin a los juicios que amenazaban con llevarlos ante los tribunales, aprobando las leyes de "Obediencia Debida" y "Punto Final". Y cuando eso no fue suficiente, se apeló a los indultos presidenciales durante el primer gobierno de Carlos Menem. En Uruguay, en cambio, sin necesidad de sublevarse abierta y públicamente, los militares lograron que se promulgara una ley de impunidad. (Morales, 2009, p. 64) 


\section{El anticomunismo y el Plan Cóndor}

La lucha contra el comunismo internacional estuvo enmarcada en el plan Cóndor, de allí surgieron las mayores alianzas estratégico-militares, al igual que dio lugar a la masiva violación a derechos humanos. Por medio del plan Cóndor "las fuerzas de seguridad de los Estados del Cono Sur se coordinaron, al más alto nivel de comando, para detener ilegal o arbitrariamente, secuestrar, torturar, asesinar o desaparecer miles de personas" (Corte IDH, 2006, p. 3). De la mencionada operación surgió la Alianza Anticomunista Americana (AAA), la cual complementaba las acciones de terror contra el grueso de la población. Las anteriores acciones tenían un enorme componente militar involucrado, además tuvieron la participación de los Estados Unidos quienes mezclaron anticomunismo y contrainsurgencia y crearon un discurso para la persecución a comunistas, el cual fue extendiéndose en América con posterioridad a la segunda guerra mundial. Martorrell (1999) señala que esta estrategia represiva militar “permitía violar la legislación internacional y cometer numerosos crímenes y hacer persecución, detención y entrega de opositores políticos” (p. 36).

Henry Kissinger fraguó la Escuela de las Américas y el Plan Cóndor, entre muchas otras maneras de intervención de los EE.UU en la región. Hoy se conoce que en este sitio de enseñanza se diseminó lo aprendido por los militares norteamericanos con los franceses, entre otras cosas, la formación de organizaciones paramilitares. Se calcula que en la Escuela de las Américas (US Army Scholl of the Américas, USARSA), sin ser la única dedicada a tales propósitos, 100.000 militares latinoamericanos fueron formados allí, entre ellos, 4.629 colombianos, solamente entre 1950-1970. Pero antes de esta influencia francesa, Estados Unidos ya había implementado los escuadrones de la muerte o paramilitares en países de América Latina (Velásquez, 2007); en dicha escuela el sentimiento anticomunista era vital, "allí se formaron varios de los dictadores de países de la región como Noriega en Panamá, Bánzer en Bolivia y en Argentina, Rodríguez, Galtieri y Viola” (Martorell, 1999, p. 60).

De ese modo, el imperio norteamericano no solamente quería consolidar su hegemonía en Suramérica, al igual que su poder militar, lo que fortalecía en últimas su dominación y liderazgo, además de privilegiar el ascenso al poder de militares en los diferentes Estados de la región. El enfoque único y característico era de acciones represivas al interior de cada país y especialmente atacar a los detractores políticos o insurgentes de cualquiera de los Estados partícipes de esa operación por medio de la "práctica sistemática de detenciones arbitrarias, torturas, ejecuciones y desapariciones perpetradas por las fuerzas de seguridad e inteligencia” (Corte IDH, 2006, p. 51). Era tan masiva la violación a derechos humanos que la sociedad la entendía como necesaria y prácticamente legitimó las estatales acciones criminales, por esta vía la impunidad campeó durante décadas.

La operación era una forma de afianzar y consolidar el poder del terrorismo de Estado como praxis cotidiana; fomentó el irrespeto por los derechos humanos, 
Esto es, no sólo no protegieron los derechos humanos de sus propios ciudadanos sino que conspiraron para violar las normas internacionales de recaudo: el derecho de asilo, la protección a los refugiados, el habeas corpus y los cuidadosamente elaborados procedimientos de extradición de quienes enfrentan cargos por crímenes cometidos en un país y son arrestados en otro.

Como un tratado secreto, el Cóndor elevó los crímenes contra los derechos humanos al más alto nivel de política de Estado, bajo el control directo de mandatarios y ministros. Y su existencia como instrumento oficial de seis naciones impide que estos regímenes expliquen sus crímenes contra los derechos humanos como actos aislados de funcionarios alterados o agentes corruptos. (Dinges, 2004, pp. 17-18)

Ante el desconocimiento del derecho internacional y en la retórica estatal de procurar garantizar al menos: la vida, honra y bienes de los ciudadanos, por esas razones ha habido enfrentamientos violentos con los grupos subversivos y su guerra de guerrillas, que en muchos casos incluyen el terrorismo como útil método de terror. Indudablemente en los enfrentamientos contra las fuerzas subversivas o terroristas, se sabe no hay reglas muy claras y como consecuencia de ello hay un rechazo y violación permanente al derecho internacional humanitario y, por supuesto, a los derechos humanos. Este sofisma ha permitido la legitimización de acciones terroristas por parte de los gobiernos, las cuales son tan execrables como el accionar terrorista subversivo.

Para muchos la génesis del terror estatal en Latinoamérica tiene su origen en el "Plan Cóndor" nacido en el sur del continente en 1975 con el fin de perseguir y torturar a los adversarios políticos por fuera de las fronteras (Álvarez, 2005, p. 86), los cuales creaban una sensación de inseguridad para los detentadores del poder. Fue una época en la que se empezaba a hablar de la manida 'seguridad': nacional, de la pública o de la seguridad ciudadana, etc., sin llegar al actual concepto de seguridad humana que "se basa en el desarrollo del derecho internacional de los derechos humanos y se enfoca hacía la seguridad de las personas más que en la seguridad de los Estados" (Odello, 2008, p. 290-291). Por lo dicho, la seguridad humana es vital para la conservación de la sociedad, empero, durante el desarrollo de las dictaduras militares en el continente, la violación a derechos humanos fue una constante.

Muy unida a la Operación Cóndor se encontraba la central de inteligencia americana (CIA), la cual estaba al tanto de cómo funcionaban los servicios de inteligencia de la región y cómo especialmente existían torturas y asesinatos ejecutados estos por militares de diferentes países, todo con una finalidad de evitar brotes de inconformismo señalados por ellos como comunistas.

Si bien la Operación Cóndor fue articulada por los "servicios de inteligencia” de los países del Cono Sur en 1975: Argentina, Bolivia, Brasil, Chile, Paraguay y Uruguay, su práctica de manera indirecta- era efectuada en Colombia, Venezuela y Perú. Aunque los casos más 
conocidos, en los que se considera más importante la represión son los de Argentina y Chile. Allí, el "Plan Cóndor” tenía la misión de llevar a cabo una acción represiva coordinada, pero que degeneró en un "plan sistemático de detenciones ilegales, torturas, desplazamientos forzosos de personas, asesinatos y desaparición de numerosas personas” (Serrano, 2000, p. 117).

\section{Los objetivos del Plan Cóndor}

Los objetivos principales de la denominada “Operación Cóndor" eran diversos y dependían de las necesidades de cada país, por esa razón los estrategas de la operación en la CIA norteamericana dirigido por Henry Kissinger y, entre otros, el jefe del servicio secreto de Chile (DINA) Manuel Contreras, tenían una especie de 'portafolio' de formas de enfrentar a los opositores ya fueran de carácter civil o militar y, por supuesto, su principal elemento eran las acciones de terror e, inclusive, de terrorismo trasnacional.

Las amplias posibilidades de aplicación al igual que el éxito demostrado eran su mejor carta de presentación. Esta forma criminal servía a los gobiernos y podía ser adecuada o mejorada según las necesidades locales, iban dirigidas contra individuos considerados por ellos mismos como indeseables opositores al gobierno, en últimas la estrategia implementada en cada país tenía sus propios rasgos distintivos como detenciones ilegales, torturas, desaparición forzadas y demás.

Existían acciones comunes entre los diferentes gobiernos enmarcados en el "Plan" el cual era tanto en el ámbito de la cooperación militar y policial. En últimas que las fronteras no fueran un obstáculo para el ejercicio de la "guerra sucia" en la que tanto la reciprocidad permanente en cuanto a la cantidad y calidad de información sobre individuos incómodos para el gobierno, como las prácticas criminales eran comunes.

El plan criminal denominado 'Cóndor' se empezó a gestar mucho antes de que Salvador Allende Gossens, uno de los fundadores y líder del Partido Socialista, fuera elegido presidente de Chile desde el 24 de octubre de 1970 hasta su muerte, a través de un golpe de Estado el 11 de septiembre de 1973, muerte dirigida por el general chileno Augusto Pinochet Ugarte.

La desaparición forzada de personas, el fusilamiento de opositores al sistema aparece a la par que la DINA, que en opinión de Baltazar Garzón el juez español que conociera de estos crímenes, era "una organización fuera de la estructura orgánica institucional de las Fuerzas Armadas, dependiente de Pinochet que tuvo por finalidad llevar a cabo una serie de actividades criminales tales como el secuestro, torturas y asesinatos" (Martorell, 1999, p. 26).

Los llamados "archivos del terror" recuperados por los jueces argentinos, antes que por los jueces españoles y por la CIDH, han permitido saber que la operación Cóndor se identificaba 
La Operación Cóndor y el terrorismo de Estado

por un encubrimiento de las operaciones transfronterizas dirigidas contra opositores de los gobiernos integrantes del plan. En esa dirección tenían escuadrones de la muerte, quienes cometían toda suerte de crímenes atroces, especialmente de lesa humanidad. En abril de 2010 con la condena al ex general Reynaldo Bignone a 25 años de prisión, a quien fuera presidente de facto de Argentina, por hechos sucedidos antes y durante su mandato entre 1982 y 1983.

Las características violentas e ilegales de la represión eran cada vez mayores y su expansión era total, ciertamente había muy pocos jueces que conocieran de las arbitrariedades que en materia penal cometía el gobierno, esta es una de las principales características del terrorismo de Estado. A estas solamente hacían frente las esporádicas y muy limitadas organizaciones defensoras de derechos humanos, quienes a consta inclusive de su propia vida, organizaban diversas formas de conocer la verdad de lo sucedido en procura de evitar la impunidad.

Se ha probado en varios procesos penales seguidos contra militares vinculados directamente con el mencionado plan criminal, que el denominado "Operativo Cóndor” tenía como objetivo eliminar al terrorismo, especialmente el marxista en el continente. Al respecto, Boccia (2006) señala que de manera

Secreta, implicaba la formación de grupos especiales de los países
miembros, que deberán viajar por cualquier parte del mundo hacia
países no-miembros, para llevar a cabo castigos incluido el asesinato
contra terroristas o simpatizantes de organizaciones terroristas de los
países miembros del "Operativo Cóndor". Por ejemplo, en el caso de
que un terrorista o simpatizante de una organización terrorista de
un país miembro del "Operativo Cóndor" se encontrara en un país
europeo, se enviaría un grupo especial del "Operativo Cóndor" para
localizar y vigilar al objetivo. Cuando hubiera terminado la operación
de localización y vigilancia, se enviaría un segundo grupo del "Operativo
Cóndor" para llevar a cabo el castigo real contra el objetivo. Los
grupos especiales serían provistos de documentación falsa de los países
miembros del “Operativo Cóndor". (p. 156)

El Estado usaba el derecho penal y lo aplicaba con rigor en aquellos que disentían de sus políticas, las campañas mediáticas para ocultar los crímenes estatales, unidos a una aparente legitimación social, eran frecuentes. Todo bajo el sofisma de la posibilidad de repetir en este lado del mundo el triunfo de la revolución cubana.

De esta macrooperación se desprendían otras que hacían más efectivos los objetivos que se perseguían así, en opinión de Paredes (2004), la Operación Cóndor permitía el seguimiento, traslado y eliminación de exiliados políticos en otros países que hacían parte de la operación Cóndor. 
En este sentido, la sociedad veía en el derecho penal la solución, a parte de los problemas derivados de la seguridad interna, y señalaba como de su mano y con la jerarquía militar al frente del mismo la seguridad nacional no se vería afectada. De ahí que la gran masa social se veía abocada a aceptar sin discusión la violencia del gobierno por medio del estamento militar, dirigida a proteger tanto la seguridad interna como la externa, ante el supuesto advenimiento del terrorismo internacional, que provenían del arrollador "ataque comunista". Siempre existió la prolijidad en cuanto a extender el plan Cóndor al resto de América para "la persecución, los encarcelamientos y asesinatos de militantes y dirigentes revolucionarios en cualquier país, serían parte de una guerra que cada Estado libraba, como la región misma, contra la amenaza comunista" (De Gori, 2009, p. 64). Era pues la forma en que se visibilizarían auténticos criminales que, bajo el sofisma de ser reaccionarios frente a los revolucionarios encabezados por las guerrillas, efectuaban terrorismo de Estado.

Para la sociedad de los países del Cono Sur, y luego para las demás naciones del continente, el enorme dilema surgía entre si disentía de esas acciones ilegales o si se mantenía incólume ante la barbarie, lo que de algún modo le garantizaba su propia seguridad. Esta situación de omisión de denunciar fue utilizada a granel por el estamento militar que con el apoyo gubernamental y la pasividad de buena parte de la sociedad logró el ascenso, la permanencia y la expansión del poder militar, lo que en últimas consolidó una derecha o ultraderecha que no deseaba que nada ni nadie entorpeciera sus actividades criminales.

Con rasgos característicos de un terrorismo estatal, con ciertas anomias que permitían catalogar como terrorista a aquellos individuos a quienes el gobierno consideraba como enemigos del Estado y, en consecuencia, objetos del reproche penal, en el mejor de los casos, y como víctimas de innumerables delitos cometidos por agentes estatales.

\section{El funcionamiento del Plan Cóndor}

El Plan Cóndor como asociación entre los máximos dirigentes militares de las dictaduras de Argentina, Bolivia, Brasil, Chile, Paraguay y Uruguay permitía la persecución, secuestro y, en muchas ocasiones, el homicidio de ciudadanos de los nombrados países. Los integrantes de los servicios secretos chilenos, argentinos, paraguayos y brasileños se reunieron para orquestar el Plan Cóndor. En este contubernio Augusto Pinochet era el Cóndor 1, su subordinado Manuel Contreras el Cóndor 2, el General Rafael Vilera Cóndor 3, entre otros; así nacía "un espacio de terror para perseguir y torturar a los adversarios políticos más allá de las fronteras nacionales” (Álvarez, 2005, p. 86).

En este sentido, las operaciones se dividían en tres grandes áreas: 
La Operación Cóndor y el terrorismo de Estado

\begin{abstract}
En las actividades de vigilancia política de disidentes exiliados o refugiados; en la operación de acciones encubiertas o clandestinas de contrainsurgencia, y en acciones conjuntas de exterminio dirigidas a grupos o individuos específicos, para lo cual se conformaban equipos especiales de asesinos que operaban dentro y fuera de las fronteras de sus países (Corte IDH, 2010, p. 1).
\end{abstract}

Casos como el del hijo del poeta Juan Gelman han llamado la atención de los defensores de los derechos humanos y de la Corte Interamericana de Derechos Humanos (Corte CIDH); estos repugnantes hechos tuvieron ocurrencia en la dictadura cívico militar de los años 1973 y 1985 en Uruguay, en la que se recurrió a acciones de orden sistemática y graves violaciones a los derechos humanos cometidas por parte de agentes de la dictadura militar y, específicamente, de la llamada Operación Cóndor. Así pues, para el día 24 de agosto de 1976, los esposos María Claudia García Iruretagoyena Casinelli y Marcelo Ariel Gelman Schubaroff de nacionalidad argentina, fueron detenidos y posteriormente separados por parte de militares uruguayos y argentinos.

La Corte CIDH, en este asunto, ha dicho que el Estado de Uruguay reconoció parcialmente su responsabilidad internacional "por la violación de los Derechos Humanos de María Claudia García Iruretagoyena de Gelman y María Macarena de Gelman García durante el gobierno de facto que rigió en Uruguay entre junio de 1973 y febrero de 1985 (Corte IDH, 2010). Gobierno de facto en el que como ya se dijo se practicaba terrorismo de Estado y era parte de la Operación Cóndor, de tal modo que el terror y el terrorismo estatal se expandiera.

\title{
La Operación Cóndor y el terrorismo de Estado
}

Los regímenes dictatoriales en los que existió el Plan Cóndor se basaron fundamentalmente en la práctica de un terrorismo estatal, dentro del terrorismo de Estado, una de sus principales particularidades era lograr la impunidad de los crímenes cometidos por ellos. Tal como lo ha señalado Torres, este tipo de terrorismo utilizado frecuentemente por los gobernantes que pertenecieron a la llamada "Operación Cóndor", el terrorismo de Estado se caracteriza por:

\footnotetext{
Concebir, planear y poner en marcha la ejecución y el control de un plan criminal secreto, con acciones legales e ilegales, para la represión de cualquier modo de personas o grupos, contempladas como un problema para los fines estatales; esto es, para la existencia y permanencia de la seguridad de los gobernantes y sus mentores, padrinos, patrocinadores, etc., más cercanos al poder y de todo su poder, durante el mayor tiempo posible. Para lograrlo, se requiere de una serie de componentes. (Torres, 2010, p. 180-181)
} 
Entre estos destacan la "criminalización de la resistencia popular e imposición de obediencia a través del disciplinamiento social con el derecho penal” y la "justificación de la violencia institucional y permanente impunidad mediante la manipulación de los medios de comunicación” (Torres, 2010, p. 180-181).

A través de esta asociación ilícita se gestó y ejecutó una pluralidad de delitos que tenían como principal objetivo consolidar más y mejores privilegios, en definitiva, perpetuar su poder, dentro de esa dinámica criminal recolectan, intercambian información secreta, se hacían intercambios extrajudiciales de presos políticos; fue así como los militares ejecutaron una política estatal de exterminio, dirigida contra opositores reales o imaginarios del gobierno, por lo que implementaron una estructura paraestatal, siguiendo una política criminal de Estado, que posibilitaba a los detentores del poder público ocultar las atrocidades y evitar la aplicación del Derecho Internacional y las garantías de los derechos humanos, con total irresponsabilidad e impunidad (McSherry, 2005). Esta es una característica propia de regímenes en los que se efectúa el terrorismo estatal, lo diferente aquí radicaba en que los Estados participantes realizaban de manera flagrante, masiva y sistemática una serie de crímenes de manera trasfronteriza, es decir sin tener en cuenta el principio de soberanía de los pueblos. Ha dicho la CIDH que:

\footnotetext{
Esa coordinación transnacional fue muy organizada, con entrenamientos constantes, sistemas de comunicación avanzados, centros de inteligencia y planificación estratégica, así como con un sistema paralelo de prisiones clandestinas y centros de tortura, con el propósito de recibir a los prisioneros extranjeros detenidos. Ciudadanos de varios países de la región fueron retenidos y luego trasladados a sus países, donde fueron entregados a cuerpos militares de la Operación Cóndor. (Corte IDH, 2010, p. 1)
}

\section{La doctrina de la seguridad nacional como terrorismo de Estado}

Es evidente que el respeto a los DH de algún modo caracteriza grandes posibilidades de lograr la paz, asimismo la seguridad en sus diversas facetas permite que la preservación de libertades garantice los derechos humanos. No se puede sustraer que en la globalización actual existe una interrelación entre derechos humanos y tranquilidad pública, es decir, la seguridad personal como derecho humano, la seguridad personal y la nacional, todas ellas conforman un todo indispensable para hablar de paz.

A pesar de la sentida y por supuesta necesidad de seguridad (de cualquier clase de seguridad) esto no implica la inexistencia de límites frente a los que no deba responder el gobierno; en ese aspecto la consecución de seguridad ha desenfrenado en violencia estatal, a la que pareciera no 
existen ni límites ni existe una justicia nacional o internacional que le ponga freno. Cuando se utiliza el terrorismo, así sea para combatir el terrorismo, esas 'seguridades' traen más caos y violencia. Debido a la aplicación de la doctrina de la seguridad nacional, las enormes diásporas de personas determinadas como subversivas, comunistas, terroristas, etc., por diferentes gobiernos de Latinoamérica conllevó a que "miles de ciudadanos del Cono Sur buscaran escapar a la represión de sus países de origen refugiándose en países fronterizos. Frente a ello, las dictaduras crearon una estrategia común de 'defensa” (Corte IDH, 2006, p. 26).

La posición de defensa de la seguridad democrática, nacional o colectiva, que como parte de las políticas implementadas por los EE.UU en Latinoamérica llegaron a calar en los gobiernos del continente, sirvieron para la protección y para la seguridad de los gobiernos, no de los ciudadanos. Precisamente, fue el Plan Cóndor a través del cual se llevaron a cabo políticas que permitían la persecución de delitos que teóricamente atentaban contra las instituciones de los países miembros de ese macabro plan. La aplicación de la doctrina de Seguridad Nacional en América Latina permitió que "se violaran los derechos humanos contra miembros reales o imaginarios de grupos subversivos” (De Roux, 2010, p. 137). De igual modo, Torres explica que siendo una doctrina militar cuya aplicación suponía la intervención constante y sistemática de las Fuerzas Armadas en la vida política, esta se relacionó con las dictaduras por medio del Plan Cóndor que coordinó desde la Casa Blanca de Washington, Henry Kissinger (Torres, 2012).

Debido a las peculiaridades de los integrantes de los grupos subversivos y sus tácticas, en algunos momentos estos se organizaron en células y en ocasiones no usaban uniforme, o distintivos que permitieran su diferenciación. Esto permite que, aquellos quienes los combaten, que no son otros que los cuerpos y fuerzas de seguridad del Estado, lleguen a consideraciones tan extremas que para combatirlos eficazmente acudan o empleen la llamada "guerra sucia". Así fue como "los militares en Argentina hacían lo mismo que los subversivos, es decir, no usaban uniforme y actuaban en células, lo que les permitía violar los derechos humanos sin mayores problemas" (Moyano, 1999, p. 277).

En Chile, Argentina y Uruguay la tortura como método de terror fue utilizado por los militares y la forma de evitar las pruebas que posiblemente los incriminaba respecto a ese y otros crímenes fue asesinar a sus víctimas, como bien señala Ignatieff (2005) “cuando la tortura se convierte en una práctica de Estado, lleva consigo otras consecuencias que pueden dañar a la reputación moral y la legitimidad política de un Estado” (p. 187). De algún modo, se aceptan implícitamente las torturas como parte del interrogatorio, lo cual es a toda costa "un mal menor", de tal manera que para evitar el terrorismo, incluso se permita hasta el asesinato del terrorista, ya que es mejor que este muera "en comparación con permitir que murieran miles de personas” (Ignatieff, 2005, p. 24). No sobra decir que fuerza pública (ejército y policía) han recurrido a la tortura como método 'preventivo' para eliminar la subversión. 
Situación muy similar de violencia política y terrorismo de Estado se vivió en el Perú en el gobierno de Fujimori (Mansilla, 1999, p. 277) aquí en Colombia, el Estado le agregó una solución "poco afortunada", el combatir el terrorismo con terror o terrorismo (Waldmann y Reinares, 1999, p.268), con lo cual la situación adquirió características dramáticas cuando al problema de las guerrillas y al terrorismo que estas practican se les agregó el narcotráfico, por lo que hubo de efectuarse una "guerra sucia". Al amparo de la denominada "defensa nacional", se crearon los “grupos de autodefensa”, que luego han sido denominados 'paramilitares', estos han tenido sustento legal de tiempo atrás y han contado en no pocas ocasiones con el apoyo activo o la omisión de las autoridades estatales.

\section{Las sentencias penales contra jefes de Estado y jerarcas militares}

Cada vez es mayor el conocimiento de la verdad sobre la operación Cóndor y el terrorismo de Estado, recientemente se supo más de esa confabulación terrorista gubernamental por medio de las decisiones de los jueces del Tribunal Oral Federal 1 emitido en Buenos Aires, Argentina, del 27 de mayo de 2016, en la que se dictaron 15 condenas contra autores y partícipes de la operación Cóndor, este juicio, al igual que otros que lo antecedieron (en España, o en la Corte Interamericana de Derechos Humanos) plantean algunas inquietudes, que desde el plano del derecho penal internacional dan lugar a disquisiciones de un lado, respecto a la responsabilidad penal, específicamente de los jefes de Estado, y por otro lado, en torno al principio de legalidad.

Acerca de la primera cuestión (castigo a jefes de Estado involucrados en la operación Cóndor) han existido condenas contra estos, así fue como el dictador Alfredo Stroessner, quien dirigiera los destinos del Paraguay en 1954 hasta 1989, fue condenado por un juez de su país, por su participación en la operación Cóndor, pero este murió en el exilio en 2006.

Lo mismo sucedió con Augusto Pinochet Ugarte, quien fuera jefe de Estado entre 1973 y 1990, fue procesado por diversos crímenes en España en aplicación del principio de justicia universal, no obstante, el dictador chileno murió en 2006 sin haber sido condenado.

Por su parte Jorge Videla, jefe de Estado en la Argentina entre 1976 y 1983, en julio de 2001 "fue procesado por asociación ilícita debido a su participación en la operación cóndor" (Álvarez, 2005, p. 86). Siendo este expresidente el primer jefe de los países integrantes del mencionado plan, que en un Tribunal de Córdoba Argentina, en 2010, es condenado a cadena perpetua por delitos de lesa humanidad, cometidos durante la última dictadura militar Argentina. Videla murió en 2013.

Estos emblemáticos casos son indudablemente una forma de hacer justicia por parte de algunos jueces, sin embargo, esto oculta una realidad respecto a que los castigos que en materia 
La Operación Cóndor y el terrorismo de Estado

penal se han surtido, lo han sido para los mandos militares que si bien eran jerarcas, no eran precisamente los jefes de Estado. Es decir, la responsabilidad penal ha sido determinada por el dominio de la acción o por el dominio funcional, o del hecho en algunos eventos y no por el dominio de la voluntad. La aplicación de la teoría del dominio de la voluntad permitiría el castigo a los jefes de Estado, a los cuales se hallaban supeditados los militares en cuestión. La inexistencia de acciones penales contra los determinadores o los autores mediatos no ha permitido que todavía subsista una dinámica criminal que mantiene la impunidad y que en consecuencia no permite que se haga justicia.

En el caso de criminales como Pinochet, o de menor calado como Adolfo Scilingo Manzoro, se aplicó con éxito el principio de justicia universal (PJU). Con la aplicación del principio de justicia universal realizado, especialmente en España, se pudo conocer que existía en el Cono Sur de América Latina un grupo de individuos que participaron en la comisión de numerosos crímenes, amparados en el Estado que permitió que algunos de sus agentes se convirtieran en una organización criminal ilícita que llevaba a cabo crímenes cometidos desde el Estado con la finalidad de preservarlo de los embates de individuos comunistas.

Torres determina que en Colombia este principio proviene de las obligaciones que dimanan de los tratados y convenios internacionales suscritos y ratificados por Colombia. Siendo pues, otras formas de aplicación del derecho penal internacional, con lo cual, la justicia universal en materia penal hace parte sustancial del derecho penal colombiano. Agrega que:

De ningún modo el Estado deja de ser el principal garante del contrato social contraído con sus ciudadanos cuando deja que se aplique el PJU, los derechos de ningún ciudadano se ven vulnerados; al contrario, los derechos de algunos criminales ejecutores de crímenes considerados graves se ven minimizados en aras de proteger la colectividad. De la misma manera, el principio de soberanía nacional tampoco se resquebraja, sigue predominando ya que el PJU es de aplicación muy especial y para cierto tipo de crímenes en determinados casos. (Torres, 2013, p. 105)

Ahora bien, la segunda cuestión planteada es respecto a la legalidad, a lo cual, de entrada, hay que señalar que ciertamente es flexible. Sobre ella descansa la seguridad jurídica, así es que los ciudadanos pueden conocer cómo y debido a qué razones han sido o pueden ser objeto de sanciones penales; el objetivo del principio de legalidad es evitar los excesos de los Estados. La Corte Constitucional ha expresado que:

El principio de legalidad garantiza la seguridad jurídica de los ciudadanos por cuanto les permite conocer cuándo y por qué motivos pueden ser objeto de penas ya sea privativas de la libertad o de otra índole, evitando 
de esta forma toda clase de arbitrariedad o intervención indebida por parte de las autoridades penales respectivas. (Corte Constitucional, 1994, s.p)

En los eventos de graves crímenes que afecten normas de ius cogens, como son los crímenes de guerra, agresión, lesa humanidad y aquellos relativos al Derecho Internacional Humanitario, buena parte de la doctrina cree necesario flexibilizar el principio de legalidad, es decir, en casos que tengan que ver con el derecho penal internacional, tal como es el caso de la Operación Cóndor, el derecho penal aplicable se flexibiliza cuando el análisis se hace desde el principio de legalidad.

Por su parte, en la Corte Interamericana de Derechos Humanos la primera condena judicial se dio el 22 de septiembre de 2006, así fue como, por unanimidad, se admitió la responsabilidad internacional del Estado paraguayo por violación de los derechos consagrados en varios artículos de la Convención Americana sobre DDHH.

La CIDH el 24 de febrero de 2010,

Declaró, por unanimidad, que el Estado de Uruguay es internacionalmente responsable por: a) la desaparición forzada y la violación de los derechos al reconocimiento de la personalidad jurídica, a la vida, a la integridad personal y a la libertad personal, en perjuicio de María Claudia García Iruretagoyena Casinelli; b) la violación de los derechos al reconocimiento de la personalidad jurídica, a la vida, a la integridad personal, a la libertad personal, a la familia, al nombre, a los derechos del niño y a la nacionalidad, en perjuicio de María Macarena Gelman García Iruretagoyena, por lo que constituyó una forma de desaparición forzada desde su nacimiento hasta el momento en que recuperó su verdadera y legítima identidad; c) la violación de los derechos a la integridad personal y a la protección de la familia, en perjuicio del señor Juan Gelman, y d) la violación de los derechos a las garantías judiciales y a la protección judicial, en relación con las normas pertinentes de la Convención Americana y de la Convención Interamericana sobre Desaparición Forzada de Personas, por la falta de investigación efectiva de los hechos del presente caso, en perjuicio de Juan Gelman y María Macarena Gelman. Además, el Estado ha incumplido la obligación de adecuar su derecho interno a la Convención Americana, como consecuencia de la interpretación y aplicación que le ha dado a la Ley de Caducidad de la Pretensión Punitiva del Estado respecto de graves violaciones de derechos humanos. (Corte $\mathrm{CIDH}$, 2010, p. 3) 
La Operación Cóndor y el terrorismo de Estado

Norris muestra que los orígenes de las leyes de impunidad estaban vigentes en América desde 1978 son:

El resultado del terrorismo del Estado y representa la política de los terroristas para encubrir los hechos. Por lo general, estas leyes no se han invocado para su propósito tradicional. No se han adoptado para estimular el retorno a la paz o para reintegrar a los presos políticos, refugiados o exiliados, sino para dar legitimidad al terrorismo del Estado y para evitar el enjuiciamiento de los agentes del terrorismo oficial. Las leyes de impunidad de este período se pueden dividir en tres categorías: (1) auto amnistías decretadas por gobiernos militares, (2) medidas adoptadas por gobiernos civiles bajo presión o influencia militar, y (3) amnistías promulgadas en cumplimiento con los acuerdos de Esquipulas II. (Norris, 1992, p. 110)

En virtud de este acuerdo suscrito en 1987, las repúblicas centroamericanas se obligaron a declarar la amnistía cuando era necesario y asegurar la inviolabilidad de la vida, la libertad en todas sus formas y la propiedad y seguridad de las personas a quienes la amnistía fuera aplicable.

No obstante, como se sabe estas leyes de auto impunidad fueron derogadas a raíz de varios fallos de la Corte IDH, en algunos casos han existido condenas en tribunales internacionales, ante los cuales la Corte IDH no se ha opuesto. Al contrario, ha abierto la posibilidad de aplicación de justicia de carácter universal, en este sentido señaló:

Paraguay, al igual que los demás Estados partes en la Convención, deben colaborar entre sí para erradicar la impunidad de las violaciones cometidas en este caso mediante el juzgamiento y, en su caso, sanción de sus responsables y a colaborar de buena fe entre sí, ya sea mediante la extradición o el juzgamiento en su territorio de los responsables de los hechos. (Corte IDH, 2006, p. 98)

Las operaciones del Plan Cóndor, siendo clandestinas, incluían la comisión de crímenes de lesa humanidad, por ejemplo,

la sustracción, supresión o sustitución de identidad y apropiación ilícita de niños y niñas, para lo cual mujeres embarazadas eran detenidas en el marco de las referidas operaciones y mantenidas vivas. En numerosos casos, los niños y niñas recién nacidos o nacidos en cautiverio eran entregados a familias de militares o policías o de terceros, luego de que sus padres fueran desaparecidos o ejecutados. (Corte IDH, 2010, p.1) 


\section{Conclusiones}

Los militares de la región que recibían instrucción de los Estados Unidos y los políticos de diversos partidos, con el ánimo de lograr o mantener sus privilegios, se dieron a la tarea de eliminar cualquier brote de inconformismo, ya fuera inconformismo legal o ilegal, por medio de sus políticas violatorias de los derechos humanos a gran escala y con la utilización de cruentos métodos, las violaciones fueron sistemáticas y duraron años. Esto dio lugar a que en casi toda Latinoamérica, estamentos militares en contubernio con la dirigente clase política, llevaron a cabo acciones contra personas u organizaciones que en su opinión eran adeptas al comunismo o eran terroristas. Fue así como instauraron una organización clandestina con un carácter internacional para efectuar un terrorismo estatal. Además de lo señalado, "la implementación de la economía de los Chicago Boys sirvió como un gran frente de batalla no solamente contra los opositores sino contra toda la sociedad chilena” (Martorell, 1999, p. 75).

Entre Argentina, Bolivia, Chile, Paraguay y Uruguay se creó el Plan Cóndor, dirigido por las cúpulas militares, el cual funcionaba como una gran oficina que tenía como finalidad recoger y proporcionar los antecedentes de todos aquellos individuos que fuesen 'enemigos' de cualquiera de los gobiernos que pertenecían al plan e inclusive a otros países. En esa componenda criminal, se contó con la colaboración eficaz de la incursión de lo militar a lo civil llega a tal punto que hubo tribunales militares juzgando a civiles por conductas que de ningún modo tenían la más mínima relación con la milicia.

Con esa finalidad, la soberanía era cedida por razones de "seguridad nacional”, era una forma de consolidar los poderes dictatoriales y de mantener un monopolio del militarismo en la región.

Las operaciones policiales y militares que en torno a eliminar las barreras de la información y la persecución a personas que perseguían cambios en sus países, se dieron con ocasión de la puesta en marcha de la operación Cóndor; este sin embargo no fue el único objetivo, el otro era eliminar los inconvenientes derivados de las expansiones de inconformes con las políticas de sus gobiernos en los países de la región. Era la principal forma de eliminar la incipiente insurgencia, la doctrina de la contrainsurgencia que tiene sus orígenes en Francia. También se fomentaba la represión estatal de todas las maneras incluyendo las acciones criminales. A pesar de las prácticas criminales conocidas por buena parte de la sociedad latinoamericana, los demás países de la región tenían como única alternativa consentir dichas prácticas.

Estas masivas violaciones a los derechos humanos fueron conocidas años después, gracias a algunas comisiones de la verdad instauradas en diferentes países y, especialmente, por procesos iniciados contra las elites militares en países como Argentina, al igual que en la Audiencia Nacional española, la Corte de Inglaterra y la Corte Interamericana de Derechos Humanos 
La Operación Cóndor y el terrorismo de Estado

permitieron conocer los horrores que por lo menos en dos décadas se cometieron en esos países.

No obstante, que la Operación Cóndor fue enmarcada en tragedia, dolor e impunidad, y a pesar de querer eliminar corrientes de pensamiento más liberales, progresistas y de cierto modo revolucionarios, este método de terror de Estado no logró sus fines, al menos a largo plazo. Si bien en opinión de algunos el método no ha desaparecido (aunque su nombre sí), lo cierto es que cada vez hay una mayor conciencia respecto a denunciar a los terroristas que desde el Estado cometen execrables conductas que son terrorismo estatal.

En el caso colombiano, la operación Cóndor fue en parte utilizada; especialmente se hizo uso del miedo y en consecuencia el gobierno de Alberto Lleras Camargo instauró el estado de sitio durante los primeros años del Frente Nacional (Caicedo, 2016), en ese escenario de estado de excepción, que faculta al ejecutivo con poderes para enfrentar "la guerra", esa situación y en razón a su enorme éxito perduró en las décadas siguientes. Como recuerda Palacios (1995):

En el Estado de derecho colombiano, el autoritarismo se expresó en estado de sitio permanente, arma jurídica empleada para neutralizar los efectos políticos y sociales de la creciente presencia de masas urbanas, convertidas en base de opinión y de electorado, por las movilizaciones liberales. (p. 189)

En definitiva, si bien los gobiernos y los militares colombianos no hicieron parte directa de la operación Cóndor, la utilización de sus crueles prácticas tuvo en este medio un vasto uso, el que permitió consolidar una elite de poder.

Hay que destacar que para eliminar las prácticas de terrorismo de Estado es fundamental la intervención de tribunales internacionales, de tal forma que se evite la impunidad frente a estos graves crímenes de naturaleza internacional.

\section{Referencias}

Abramovich, V. y Guembe, M.J. (2006). En J. Arnold., S. Jan-Michael. y J. Woischnik. (Eds.), Estado de derecho y delincuencia de Estado en América Latina: una visión comparativa (pp. 51-73). México D.F., México: UNAM.

Álvarez, E. (2005). Abajo la democracia. El triunfo de la tiranía neoliberal. Barcelona, España: Ediciones B, S.A. 
Boccia, A. (2006). Es mi informe. Los archivos secretos de la policía de Stroessner. Asunción, Paraguay: Editorial Servilibro.

Bohoslavsky, E. (2016). Organizaciones y prácticas anticomunistas en Argentina y Brasil (19451966). Estudos Ibero-Americanos, 34-52.

Caicedo, E. (2016). Las representaciones de la revolución cubana en la sociedad colombiana: Construcción de imaginarios sociales para la justificación de estados de sitio. 1959-1961. RevistaVirtual VIeIVia Inveniendi et Iudicandi, 111-128.

Corte Interamericana de Derechos Humanos. (24 de febrero de 2010), Sentencia de 24 de febrero de 2010. [Caso Gelman vs. Uruguay].

Corte Interamericana de Derechos Humanos. (22 de septiembre de 2006), Sentencia de 22 de septiembre de 2006. [Caso Goiburú y otros vs. Paraguay].

Corte Constitucional Colombiana. (17 de marzo de 1994), Sentencia C-133, MP [Carlos Gaviria Díaz].

De Gori, E. (2009). Doctrina de Seguridad Nacional y politicas de contrainsurgencia en Honduras. Buenos Aires, Argentina, Prometeo Libros.

De Roux, C.V. (2000). Humanización del conflicto y proceso de paz. En A. Camacho., A. Guizado. y F. Leal. (Comps), Armar la paz es desarmar la guerra (pp. 137-150). Bogotá, Colombia: Centro de estudios de la realidad colombiana.

Dinges, J. (2004). The CondorYears - How Pinochet and His Allies Brought Terrorism to Three Continents. N.Y./London: The New Press.

Galeano, E. (1979). Las venas abiertas de América Latina. Montevideo, Uruguay: Editorial Monthly Review.

Ignatieff, M. (2005). El mal menor, ética política en una era de terror. Barcelona, España: Editorial Santillana.

Mansilla, F. (1999). La violencia política en Perú: un esbozo de interdisciplinario de interpretación. Monterrey, México: Universidad Nacional de Nuevo León.

Martorell, F. (1999). Operación Cóndor: el vuelo de la muerte: la coordinación represiva en el Cono Sur. Santiago de Chile, Chile: LOM Ediciones.

McSherry, P.J. (2005). Predatory States - Operation Condor and CovertWar in Latin America. Lanham: Rowman \& Littlefield Publs.

Morales, P. (2009). La ley de caducidad en Uruguay: dimensiones y tensiones de las leyes de impunidad y olvido en las democracias pos-dictatoriales del Cono Sur. En D. Feierstein. (Coord), Terrorismo de estado y genocidio en América Latina (pp. 161-182). Buenos Aires, Argentina: Prometeo Libros. 
La Operación Cóndor y el terrorismo de Estado

Moyano, J. (1999). Conflictos violentos de Europa y América Latina. Barcelona, España: editorial Paidós.

Norris, R. (1992). Leyes de Impunidad y los Derechos Humanos en las Américas: Una Respuesta Legal. Revista IIDH, (15), 47-121.

Odello, M. (2008). ¿Amenazas para la seguridad o amenazas para los individuos? El derecho internacional y los desafíos para la seguridad internacional. En J. González. (Dir.), Derechos humanos, relaciones internacionales y globalización (pp. 283-304). Bogotá, Colombia: Editorial Ibáñez.

Palacios, M. (1995). Entre la legitimidad y la violencia. Colombia 1875-1994. Bogotá, Colombia: Editorial Norma.

Paredes, A. (2004). La Operación Cóndor y la guerra fría. Revista Universum, 122 - 137.

Velásquez, E. (2007). Historia del paramilitarismo en Colombia. Historia (São Paulo), 26, $134-$ 153. DOI: http://dx.doi.org/10.1590/S0101-90742007000100012.

Waldmann, P. y Reinares F. (Comp.) (1999). Sociedades en guerra civil. Conflictos violentos de Europa y América Latina. Madrid, España: Ed. Paidós.

Serrano, J.R. (2000). La calificación de los actos contra los derechos humanos conforme a la ley española. En M. García. y D. López. (Coords.), Crimen internacional y jurisdicción universal (pp. 101-160). Valencia, España: Tirant Lo Blanc.

Torres, H. (2010). El concepto de terrorismo de Estado: una propuesta de lege ferenda. Revista diálogos de saberes, 129-147.

Torres, H. (2012). Terrorismo, antiterrorismo y seguridad en Colombia. Bogotá, Colombia: Universidad Libre.

Torres, H. (2013). La extraterritorialidad de la ley penal: el principio de justicia universal, su aplicación en Colombia Prolegómenos. Derechos y Valores, XVI (31), 99-115.

Varela, L.M. y Duque, D. (2011). Estrategia de los agrarios de Sumapaz y Oriente del Tolima durante el Frente Nacional. Revista Historia y Sociedad, 21, 171-193.

Vélez, J.C. (2014). “Los del campo”, “los de la ciudad”. Ideología organizacional, vanguardia revolucionaria campesina y aislamiento político del Ejército de Liberación Nacional, 1962-1973. Revista Análisis Político, 32-49. 